\title{
QUANTUM MEASURE OF FREQUENCY AND SENSING THE COLLISIONAL SHIFT OF THE YTTERBIUM HYPERFINE LINES IN MEDIUM OF HELIUM GAS
}

\author{
A. V. Loboda, E. V. Mischenko, Yu. V. Dubrovskaya, A. A. Svinarenko \\ Odessa National Polytechnical University, Odessa \\ Odessa State Environmental University, Odessa
}

\begin{abstract}
QUANTUM MEASURE OF FREQUENCY AND SENSING THE COLLISIONAL SHIFT OF THE YTTERBIUM HYPERFINE LINES IN MEDIUM OF HELIUM GAS
\end{abstract}

\section{A. V. Loboda, E. V. Mischenko, Yu. V. Dubrovskaya, A. A. Svinarenko}

Abstract. A problems of constructing the ytterbium quantum measure of frequency and sensing the collisional shift of the ytterbium hyperfine structure (HFS) lines in a medium of bath (He) gas are studied. Relativistic approach is used in calculating the inter atomic potentials, oscillator strengths, HFS collision shift and broadening for ytterbium atom in a medium of helium bath gas.

Keywords: quantum measure of frequency, collisional shift, ytterbium, helium gas

\section{КВАНТОВА МІРА ЧАСТОТИ І ДЕТЕКТУВАННЯ ЗСУВУ ЛІНІЙ НАДТОНКОЇ СТРУКТУРИ ІТЕРБІЯ ЗА РАХУНОК ЗІТКНЕНЬ В АТМОСФЕРІ ГЕЛІЯ}

\section{А. В. Лобода, О. В. Міщенко, Ю. В. Дубровська, А. А. Свинаренко}

Анотація. Розглянуті проблеми побудови ітербієвої квантової міри частоти і детектування зсуву за рахунок зіткнень ліній надтонкої структури (НTC) ітербія в атмосфері буферного (гелій) газу. Релятивістський підхід використано у розрахунку міжатомних потенціалів, сил осциляторів, і НТС зсуву та уширення за рахунок зіткнень для атому іттербія в атмосфері гелія.

Ключові слова: квантова міра частоти, зсув за рахунок зіткнень, ітербій, газ гелія

\section{КВАНТОВАЯ МЕРА ЧАСТОТЫ И ДЕТЕКТИРОВАНИЕ СТОЛКНОВИТЕЛЬНОГО СДВИГА ЛИНИЙ СВЕРХТОНКОЙ СТРУКТУРЫ ИТТЕРБИЯ В АТМОСФЕРЕ ГЕЛИЯ}

\section{А. В. Лобода, Е. В. Мищенко, Ю. В. Дубровская, А. А. Свинаренко}

Аннотация. Рассмотрены проблемы построения иттербиевой квантовой меры частоты и детектирования столкновительного сдвига линий сверхтонкой структуры (СТС) атома иттербия в атмосфере буферного (гелий) газа. Релятивистский подход использован в расчете межатомных потенциалов, сил осцилляторов, СТС столкновительного сдвига и уширения для атома иттербия в атмосфере гелия.

Ключевые слова: квантовая мера частоты, столкновительный сдвиг, иттербий, газ гелия 


\section{Introduction}

Studying the collisional shifts and broadening of the hyperfine structure lines for heavy elements (alkali, alkali-earth, lanthanides, actinides and others) in an atmosphere of inert gases is one of the important and actual topics of the modern sensors theory and applied atomic optics and spectroscopy [1-8]. The mentioned physical effects form a basis for creating an atomic quantum measure of frequency $[4,5]$. For a long time the corresponding phenomenon for thallium atom attracted a special attention because of possibility to create the thallium quantum frequency measure. Alexandrov and co-workers [5] have realized the optical pumping of the thallium atoms on the line of $21 \mathrm{GHz}$, which corresponds to transition between the components of hyperfine structure for the ground state, and have measured the collisional shift of this line due to buffer (bath) gas. Naturally, the inert buffer gases (He, Ar etc.) were used. The detailed non-relativistic theory of the collisional shift and broadening of the hyperfine structure lines for simple elements (light alkali elements etc.) has been developed by many authors (see discussions in refs. [1-9]). However, consideration of heavy elements faces serious difficulties related with account for the relativistic and correlation corrections. It should be mentioned also that the heavy atoms are interesting from the point of view of studying a role of weak interactions in atomic optics. In particular, calculations of the hyperfine structure line shift and broadening allow one to check the quality of wave functions and study the contribution of relativistic effects. By the way, in last years the lanthanide and actinide elements attract a great interest because of their perspectives in many applications, including the sensor physics and atomic optics devices (see refs. [2,9,10] and references there). It is very curious that until now a consistent, accurate quantum mechanical approach for calculating main characteristics of the collisional processes was not developed though many different simplified models have been proposed (see, for example $[7,8]$ ). The most widespread approach is based on the calculation of the corresponding collision cross-section, in particular, in a case of the van der Waals interaction between colliding particles. However, such an approach does not factually define any difference between the Penning process and resonant collisional one and gives often noncorrect results for cross-sections. More consistent method requires data on the process probability $G(R)$ as a function of inter nuclear distance. It should be noted that these data are practically absent at present time.

In this paper the problems of constructing the ytterbium quantum measure of frequency and sensing the collisional shift of the ytterbium $Y b$ hyperfine lines in a medium of bath $(\mathrm{He})$ gas are studied. The relativistic approach is used to calculate the interatomic potentials, oscillator strengths, hyperfine structure collision shift and broadening for ytterbium atom in a medium of helium bath gas. The basic expressions for the collision shift and broadening of the hyperfine structure spectral lines are taken from the kinetic theory of spectral lines. The exchange perturbation theory has been used for calculating the corresponding interatomic potentials. Finally, new data regarding the oscillator strengths and van der Waals coefficients for system "ytterbium-helium" are presented.

\section{Theory of collisional shift of the atomic HFS lines in the buffer gas}

First of all, to calculate the collision shift of hyperfine structure spectral lines one could use the following expression known from kinetic theory of spectral line form (see $[6,8]$ ):

$$
f_{p}=\frac{D}{p}=\frac{4 \pi w_{0}}{k T} \int_{0}^{\infty} d w(R) \exp (-U(R) / k T) R^{2} d R,
$$

where $U(R)$ is the effective potential of the interatomic interaction, which has a central symmetry in a case of the systems $A-B$ (in our case, for example, $B=H e ; A=Y b) ; T$ is a temperature, $\mathrm{w}_{0}$ is a frequency of the hyperfine structure transition in the isolated active atom; $d \omega(R)=D w(R) / w_{0}$ is the relative local shift of the hyperfine structure lines, which is arisen due to the disposition of the active atoms (say, atom of ytterbium $\mathrm{Yb}$ and helium $\mathrm{He}$ ) on a distance $R$. To calculate an effective potential of the interatomic interaction we use a method of the exchange perturbation theory [2]. To calculate a local shift one uses a method of exchange perturbation theory (we use the modified version EL-HAV [6]). Within exactness to second order terms on potential of Coulomb interaction of the valent electrons and atomic cores one can write:

$$
\delta \omega(R)=\frac{S_{0}}{1-S_{0}}+\Omega_{1}+\Omega_{2}-\frac{C_{6}}{R^{6}}\left(\frac{2}{\overline{E_{a}}}+\frac{1}{\overline{E_{a}}+\bar{E}_{B}}\right) .
$$

Here $\mathrm{C}_{6}$ is the van der Waals constant for interaction $A-B$ (e.g., a pair of $Y b-H e$; look below); I, $E_{l a, b}$ are the ionization potential and excitation energy 
on the first level for atoms A, B correspondingly; $\mathrm{S}_{0}$ is the overlapping integral; The value of $\bar{E}_{\alpha, b}$ is defined as follows:

$$
\bar{E}_{\alpha, b}=\left(I_{a, b}+E_{1 a, b}\right) / 2 .
$$

The values $\Omega_{1}, \Omega_{2}$ in the expression (2) are the non-exchange and exchange non-perturbation sums of the first order correspondingly, which are defined as follows:

$$
\begin{gathered}
\Omega_{1}=\frac{2}{N\left(1-S_{0}\right) \rho_{0}} \sum_{k} \cdot \frac{\left\langle\Phi_{0}^{\prime}(1)\left|H_{C T}^{\prime}\right| \Phi_{k}^{\prime}(1)\right\rangle V_{k 0}}{E_{0}-E_{k}}, \\
\Omega_{2}=\frac{2}{N\left(1-S_{0}\right) \rho_{0}} \sum_{k} \frac{\left\langle\Phi_{0}^{\prime}(1)\left|H_{C T}^{\prime}\right| \Phi_{k}^{\prime}(1)\right\rangle U_{k 0}}{E_{0}-E_{k}}, \\
\left.c_{0}=<\Phi_{0}^{1}(1)\left|H_{C T}^{\prime}\right| \Phi_{0}^{\prime}(1)\right\rangle /<\Phi_{0}^{1}(1)\left|\Phi_{0}^{\prime}(1)\right\rangle,
\end{gathered}
$$

where $H_{C T}^{\prime}$ is the operator of hyperfine interaction, $N$ is the total number of electrons taken into account in calculation; $E_{k}, \Phi_{k}^{\prime}(1)=F_{k_{a}}^{\prime}(1) \varphi_{k_{b}}(2 \ldots N)-$ energy and non-symmetrized wave function of state $k=\left\{k_{a}, k_{b}\right\}$ for isolated atoms A and B. The non-exchange matrix element of the Coulomb interatomic interaction is as follows:

$$
V_{k o}=\left\langle\Phi_{k}^{\prime}(1)|V(1)| \Phi^{\prime}{ }_{0}(1)\right\rangle .
$$

Correspondingly the exchange matrix element is as follows:.

$$
U_{k 0}=\sum_{i=2}^{N}\left\langle\Phi_{k}^{\prime}(1)|V(i)| \Phi_{0}^{\prime}(i)\right\rangle .
$$

Operator $V(i)$ is, for example, in a case of system $\mathrm{Yb}-\mathrm{He}$, as follows:

$$
V(i)=U_{S C F}\left(r_{a 3}\right)+U_{S C F}\left(r_{a 4}\right)-2 U_{S C F}(R)+\frac{1}{r_{b i}},
$$

where $U_{C s c f}(r)$ is the self-conjunctive field, created by the ytterbium atomic core.

Let us return to consideration of the van der Waals constant $\mathrm{C}_{6}$ for the interatomic A-B interaction. As a rule, one could use the approximate values for the van der Waals constant $\mathrm{C}_{6}$ etc. Often the sufficiently great mistake in definition of the van der Waals constants provides non-high accuracy of the inter-atomic potentials calculation and further inaccuracies. The van der Waals constant may be written as follows [2,6]:

$$
C_{6}(L, M)=C_{6,0}(L)-\frac{3 M^{2}-L(L+1)}{(2 L-1)(2 L+3)} \cdot \mathrm{C}_{6,2}(1),
$$

where $C_{6,0}(L)$ is the isotropic component of the interaction and $C_{6,2}(L)$ is the component correspond- ing to the $P_{2}(\cos \Theta)$ term in the expansion of the interaction in Legendre polynomials, where the angle specifies the orientation in the space-fixed frame.. The dispersion coefficients $C_{6,0}(L)$ and $C_{6,2}(L)$ may be expressed in terms of the scalar and tensor polarizabilities $\alpha_{0}(L ; i w)$ and $\alpha_{2}(\mathrm{~L}$; iw) evaluated at imaginary frequencies. In particular, for the helium case one may write:

$$
C_{6,0}(L)=\frac{3}{\pi} \cdot \int_{0}^{\infty} \alpha_{0}(L ; i w) \bar{\alpha}_{H e}(i w) d w,
$$

where $\bar{\alpha}_{H e}$ is the dynamical polarizability of helium. The polarizabilities at imaginary frequencies are given in atomic units as follows:

$$
\alpha_{\|}(L, M ; i w)=2 \sum_{\gamma, M_{\gamma}} \frac{\left(E_{\gamma}-E_{L}\right)|<L M| \hat{z}\left|L_{\gamma} M_{\gamma}>\right|^{2}}{\left(E_{\gamma}-E_{L}\right)^{2}+w^{2}},
$$

where $E_{\gamma}$ is the energy of the electronically excited state $\left|L_{\gamma} M_{\gamma}\right\rangle$ and the $z$ axis lies along the internuclear axis. Usually (see $[4,8]$ ) the non-relativistic Hartree-Fock basises of the wave functions are used. More sophisticated approach is based on using the relativistic Dirac-Fock wave functions (first variant) [1-7]. Another variant is using the relativistic wave functions as the solutions of the Dirac equations with different model potentials and different density functionals (the Kohn-Sham DFT theory) $[2,3]$. In this paper we have used the basis of relativistic functions, generated by the Dirac equation with the Ivanov-Ivanova model potential [11,12]. The detailed approbation of this model potential in studying spectra and radiative characteristics of the ytterbium and thallium atoms is given in refs. [13-15]. In a number of papers it has been rigorously shown that using the optimized basises in calculating the atomic electron density dependent properties has a decisive role (see discussions in refs. $[3,12,17])$. Here we will not in details discuss this question.

\section{Results and discussion}

The ground configuration for ytterbium is: $[X e] 4 f^{14} 6 s^{2}$ (term: ${ }^{1} \mathrm{~S}$ ). First of all, let us present our results for the scalar static polarizability $\alpha_{0}$ (in units of $a_{0}^{3}, a_{o}$ is the Bohr radius) and isotropic dispersion coefficient $C_{6,0}$ (in units of $E_{H} \cdot a_{0}^{6}, E_{H}$ is the Hartree unit of energy). Our results are as follows: $C_{6,0}=45,2, \alpha_{0}=169,3$. For comparison let us present the data by Chu et al: $C_{6,0}=39.4, \alpha_{0}=157.3$ and by Buchachenko et al: $C_{6,0}=44,5$. In table 1 we present our calculation results for oscillator strengths of the 
ytterbium low-lying states transitions and compare with available theoretical and experimental data [17]. The presented data confirm a complexity of the studied object. The simple coulomb approximation may hardly provide the necessary accuracy. At the same time the experimental data are not sufficiently exact $[16,17]$. In table 2 we present our calculation results (in atomic units) for the local $\delta \omega(\mathrm{R})$ (in atomic units) and observed $f_{\mathrm{\rho}}(\mathrm{Hz} / \mathrm{Torr})$ shift for system: $\mathrm{Yb}-\mathrm{He}$.

The oscillator strengths $f$ of the ytterbium low-lying states transitions

Table 1

\begin{tabular}{|c|c|c|c|c|}
\hline Transition & $\lambda(A)$ & $f,[16]$ & $f$, this paper & $f^{\text {exp }},[16]$ \\
\hline $4 f^{14} 6 s^{2}{ }^{1} S_{0}-4 f^{14} 6 s 6 p^{1} P_{I}$ & 3987,9 & 1,82 & $1,36^{\mathrm{a}} ; 1,48^{\mathrm{b}}$ & 1,$2 ; 1,38 ; 1,12 ;$ \\
\hline $4 f^{14} 6 s^{2}{ }^{1} S_{0}-4 f^{14} 6 s 7 p^{1} P_{I}$ & 2464,5 & 1,19 & $0,33^{\mathrm{a}} ; 0,38^{\mathrm{b}}$ & 0,22 \\
\hline
\end{tabular}

Note: ${ }^{\text {a }}$ - calculation with the optimized wave functions(method [16]);

b - calculation with the non-optimized wave functions (method [10]);

Table 2

The local $\delta \omega(\mathrm{R})$ (in atomic units) and observed $f_{\rho}(\mathrm{Hz} /$ Torr) shift for the system $\mathrm{Yb}-\mathrm{He}$

\begin{tabular}{|c|c|c|c|}
\hline$R$ & $\delta \omega(\mathrm{R}) \cdot 10^{2}$ & $T, \mathrm{~K}$ & $f_{0}$ \\
\hline 5 & 4,35 & 700 & 148,1 \\
\hline 6 & 1,51 & 750 & 146,0 \\
\hline 7 & 0.34 & 800 & 143,8 \\
\hline 8 & 0.08 & 850 & 141,5 \\
\hline 9 & 0.005 & 900 & 138,9 \\
\hline
\end{tabular}

Let us note that earlier we have studied the collisional shift and broadening of the HFS line for the thallium atom in the helium gas. It has been obtained physically reasonable agreement between theory and experiment for the pair of $\mathrm{Tl}-\mathrm{He}$ [6]. It is obvious that the pair $\mathrm{Yb}-\mathrm{He}$ is the more complicated system. Until now there are no any experimental or theoretical data for the $\mathrm{Yb}-\mathrm{He}$ system. Thus, our data may be considered as the first reference. So, we have studied the collisional shift of the ytterbium $\mathrm{Yb}$ hyperfine lines in a medium of helium bath gas. The presented data can be used for construction of the ytterbium quantum measure of frequency. It is of a great interest measuring the temperature frequency coefficient.

\section{Acknowledgement}

The useful critical comments of the anonymous referees are very much acknowledged.

\section{References}

1. Freeman A.J., Frankel R.H., Hyperfine interactions. - N-Y.: Plenum, 1987. - 340 p.

2. Glushkov A.V., Relativistic and correlation effects in spectra of atomic systems. - Odessa: Astroprint, 2006. - $400 \mathrm{p}$.

3. Chi X., Dalgarno A., Groenenborn G.C., Dynam- ic polarizabilities of rare-earth-metal atoms and dispersion coefficients for their interaction with helium atoms//Phys.Rev.A. - 2007. - Vol.75. P.032723.

4. Batygin V. V., Sokolov I. M., Collisional shift and adiabatic broadening of line of the hyperfine transition in the ground state of thelium in an atmosphere of the buffer helium, krypton and xenon//Opt. Spectr. - 1983. - Vol.55. - P.30-38.

5. Alexandrov E.B., Popov V.I., Yakobson N.N., The optical pumping of the thallium atoms on the line of 21GHz// Opt. Spectr. - 1979. - Vol.46. - P.404408.

6. Khetselius O.Yu., Gurnitskaya E.P., Mischenko E.V. et al, Collisional shift of the Tl hyperfine lines in atmosphere of inert gases// Spectral Line Shapes (AIP). - 2008. - Vol. 15. - P.231-234.

7. Khetselius O.Yu., Hyperfine structure of spectral lines of the heavy atoms and multicharged ions. - Odessa: Astroprint, 2008. - $210 \mathrm{p}$.

8. Sobel'man I.I. Introduction to theory of atomic spectra. - Moscow: Nauka. - 1977.

9. Khetselius O.Yu., Gurnitskaya E.P., Sensing the hyperfine structure and nuclear quadrupole moment for radium// Sensor Electr. and Microsyst. Techn. 2006. - N2. - P.25-29.

10. Gurnitskaya E.P., Sensing the de fontenau-aux-roses tokamak plasma parameters by means x-ray theoretical spectroscopy method: new advanced scheme// Sensor Electr. and Microsyst. Techn. - 2005. N4. - P.43-46.

11. Ivanov L.N.,Ivanova E.P. Extrapolation of atomic ion energies by model potential method: Na-like spectra // Atom.Data Nucl .Data Tabl. - 1979Vol.24,N2. - P. 95-101.

12. Glushkov A.V., Ivanov L.N. Radiation Decay of Atomic States: atomic residue and gauge non-invariant contributions // Phys. Lett.A. - 1992. Vol.170,N1. - P.33-38.

13. Vidolova-Angelova E., Ivanov L.N., Angelov D.A. Autoionization decay of highly excited Rydberg Tm, 
Yb states// J.Phys.B:At.Mol.Opt.Phys. - 1988. Vol.21. - P.3877-3890.

14. Vidolova-Angelova E., Ivanova E.P., Ivanov L.N., Energies and widths of autoionization states for ytterbium atom//Opt. Spectr. - 1981. - Vol.50,N2. P.243-248.

15. Bekov G.I., Vidolova-Angelova E., Ivanov L.N., Letokhov V.S., Mishin V.I., Laser spectroscopy of narrow two-timely excited autoionization states for ytterbium atom// JETP. - 1981. - Vol.80,N3. P.866-878.

16. Sukharev D.E., Theoretical determination of probabilities for electric quadrupole E2 transitions in $\mathrm{Hg}^{+} / /$Photoelectronics. - 2007. - N16. - P.146149.

17. Krunisz M.D., Coulomb approximation oscillator strengths for some transitions in rare earths// Acta Phys. Pol.. - 1982. - Vol.A62. - P.285-296. 